\title{
Músicas afrocolombianas: entre la espiritualidad y la critica social
}

\author{
Lina del Mar Moreno Tovar
}

\begin{abstract}
resumen La producción y el disfrute de la música es uno de los tópicos más comúnmente asociados con la gente de origen africano; sin embargo, más allá de las representaciones del negro músico, alegre y bailador subyacen funciones religiosas y sociales, expresadas a través de creaciones musicales, que han sido centrales para la reproducción cultural de los pueblos afrodescendientes. El artículo examina la relación histórica entre espiritualidad, crítica social y música para comprender cómo ésta ha sido vehículo de memorias corporales y así contribuir a la desnaturalización de los estereotipos que simplifican la relación de la gente negra con la creación musical.
\end{abstract}

palabras clave Afrocolombianos. Música. Fiestas. Ritos fúnebres. Espiritualidad.

\section{"Quiero contarle mi hermano \\ un pedacito de la historia negra, \\ de la historia nuestra caballero \\ $y$ dice así..."}

(Rebelión, Joe Arroyo)

Dentro del repertorio cultural compartido por amplios sectores de la población, las representaciones sobre negros y afrodescendientes suelen estar enmarcadas en la producción y disfrute de la música. En efecto, las imágenes de músicos y bailarines negros que se mueven con gracia, alegría y sensualidad o ejecutan con energía algún instrumento son quizá las más usuales dentro de nuestro sentido común; lo mismo sucede con la afirmación de que "los negros llevan la música en la sangre” y con la presunción de que son buenos bailarines y deportistas, entre otros atributos centrados en la habilidad física.

Estas representaciones se basan en ideas que cuentan con una amplia profundidad histórica. Desde su llegada a América, la corporalidad de los africanos y sus descendientes, la diferencia encarnada no solo en el color de la piel, sino en la rítmica poliforme y polisémica, fue terreno de disputa entre el rechazo, y la fascinación de la sociedad colonial que encerró el cuerpo negro en los estereotipos del baile y la sexualidad desbordada, negándole a la gente de origen africano otras cualidades relacionadas con la capacidad intelectual y la racionalidad.

La música, por supuesto, jugó un papel determinante en la construcción de las representaciones del negro alegre, desparpajado y bailador. Sin embargo, más allá de estas imágenes, que han sido útiles para diversos proyectos de dominación coloniales y post-coloniales, subyacen profundos significados sociales y espirituales que confieren a la música un papel central en el devenir histórico de los pueblos afroamericanos. En efecto, si examinamos con más cuidado la ecuación simplificada que asocia negro con música, encontramos concepciones de ésta como un elemento central tanto en la vida social y espiritual de los pueblos de África occidental involucrados en la trata, como en la resistencia de sus herederos en América. A lo largo de las siguientes páginas mostraré brevemente cómo desde muy temprano para los africanos y sus descendientes en el territorio de lo que hoy es Colombia, la música se constituyó 
en un lenguaje subversor y portador de memorias que les señaló caminos de reconstrucción cultural y adaptación a las condiciones adversas planteadas por la esclavización. En la actualidad, la música sigue siendo vehículo privilegiado mediante el cual los pueblos afrocolombianos rememoran su historia, denuncian el saqueo de sus territorios y las situaciones de violencia y desarraigo que experimentan. Este recuento me permitirá mostrar cómo, más allá de la exotización del cuerpo negro, entre los afrodescendientes la música conserva un carácter espiritual y político, una potencialidad para enunciar que ha encontrado en la corporalidad un poderoso aliado para la transmisión de esas memorias.

\section{Música y espiritualidad}

El culto a los ancestros constituyó uno de los elementos rectores en la comprensión del mundo $y$, consecuentemente, en la organización social de los pueblos africanos involucrados en la trata transatlántica (Maya, 2005; Navarrete, 1995). De acuerdo con las descripciones del sacerdote jesuita Alfonso de Sandoval, quien en la primera mitad del siglo XVII se dedicó a la evangelización de los africanos y sus descendientes que llegaban al puerto de Cartagena, el tambor jugaba un papel fundamental en los rituales de duelo destinados a convertir a los muertos en ancestros cuando, tras el entierro, el llanto daba paso al baile (Sandoval apud Maya, 2005, p. 317, 334-335).

El debate en torno a qué tanto de estas expresiones culturales logró atravesar el océano e instalarse en América ha sido álgido. En países como Colombia los legados africanos no resultan tan obvios como en otros puntos del continente que cuentan con prácticas religiosas de orientación claramente africana. Sin embargo, las fuentes históricas nos permiten saber que los esclavizados encontraron múltiples espacios de expresión que les permitieron darle continuidad a algunos de esos elementos que organizaban su comprensión y aprehensión de la realidad. Sabemos por ejemplo que durante el siglo XVII en Cartagena los cabildos, instituciones creadas en España con fines de evangelización y que en América también se dedicaron a la atención de los cautivos que llegaban enfermos, fueron espacios en los cuales la gente de origen africano pudo recrear los lloros a sus muertos, con el acompańamiento del tambor (Friedemann, 1988, p. 7); los lloros eran eventos nocturnos a las que asistían negros y mulatos quienes conmemoraban al difunto con grandes sollozos que se acompañaban de tambores en torno a los cuales los dolientes bailaban y bebían toda la noche con el ánimo de completar los rituales necesarios para que éste lograra su entrada al mundo de los ancestros (Navarrete, 1995: 85-92).

Las fiestas patronales que se celebraban en honor a la virgen de la Candelaria, patrona de la ciudad, fueron otro espacio en el que se desarrolló la íntima relación entre música y espiritualidad. Para las primeras décadas del siglo XIX el general Joaquín Posada Gutiérrez muestra a través de sus Memorias histórico politicas ${ }^{1}$, cómo las vísperas de la fiesta españoles, criollos y castas celebraban con gran profusión de bailes de salón entre los cuales los de pardos y negros libres eran los más concurridos (Posada, 1865: 202). Mientras tanto, la "gente pobre" bailaba bajo el cielo cartagenero

al son del atronador tambor africano, que se toca, esto es, que se golpea, con las manos sobre el parche, hombres y mujeres, en gran rueda, pareados, pero sueltos, sin darse las manos, dando vueltas alrededor de los tamborileros; las mujeres, enflorada la cabeza con profusión, lustroso el pelo a fuerza de sebo, y empapadas en agua de azahar, acompañaban a su galán en la rueda, 
balanceándose en cadencia muy erguidas, mientras el hombre, ya haciendo piruetas, o dando brincos, ya luciendo su destreza en la cabriola, todo al compás, procuraba caer en gracia a la melindrosa negrita o zambita, su pareja. Como una docena de mujeres agrupadas junto a los tamborileros los acompañaban en sus redobles, cantando y tocando palmadas, capaces de dejar hinchadas en diez minutos las manos de cualesquiera otras que no fueran ellas. Músicos, quiero decir, manoteadores del tambor, cantarinas, danzantes y bailarinas, cuando se cansaban, eran relevados, sin etiqueta, por otros y por otras; $y$ por rareza la rueda dejaba de dar vueltas, ni dos o tres tambores dejaban de aturdir en toda la noche (Posada, Op. Cit. p. 198).

Durante las fiestas los cabildos de negros volvían a hacer su aparición. En efecto, pese a que solo existen reportes de la existencia oficial de cabildos hasta finales del siglo XVII (Navarrete, 1995: 77), el relato de Posada Gutiérrez deja saber que para el siglo XIX éstos seguían siendo importantes formas de organización social y práctica religiosa para le gente de origen africano en Cartagena. De acuerdo con éste pasado el dos de febrero, día de la virgen, la celebración continuaba todavía una semana, durante la cual diferentes gremios asumían diariamente la responsabilidad de los festejos hasta culminar en el domingo de carnaval cuando los negros bozales, en su mayoría esclavos pero también algunos libres, organizados en cabildos mandingas, carabalíes y congos, entre otros, escogían rey, reina y príncipes y con ellos a la cabeza se tomaban la calle con el cuerpo pintado, o bien luciendo disfraces, espadas, sables y escudos de madera "cantando, bailando, dando brincos y haciendo contorsiones al son de tambores, panderetas con cascabeles, y golpeando platillos y almireces de cobre; y con semejante estruendo y tan terrible agitación, algunos haciendo tiros con escopetas y carabi- nas por todo el camino, llegaban [al cerro de] La Popa, bañados en sudor, pero sin cansarse" (Posada, 1865: 208).

Mientras que, como hemos visto, en el Caribe los cabildos fueron espacios fundamentales en la re-creación de la música como expresión de la espiritualidad negra, en el litoral Pacífico el panorama fue bien distinto ${ }^{2}$. Durante la época colonial, el peso de la iglesia en las poblaciones del Pacífico fue relativo pues, aunque según las tempranas disposiciones reales todos los negros debían ser adoctrinados en la religión católica, las condiciones climáticas y ambientales que predominan en esta región de selva húmeda tropical estimularon el ausentismo por parte de los amos, así como de los representantes de la iglesia, de modo que en amplios territorios la evangelización fue más bien laxa pues un solo doctrinero debía hacerse responsable de la salud espiritual de varios poblados y asentamientos tanto de negros como de indios (Agudelo, 2005, p. 45; Werner, 2000, p. 65; Jiménez, 2004, p. 78-81).

En el Pacífico no existieron, entonces, cabildos como los que se conformaron en Cartagena. Sin embargo, la presencia esporádica de curas sembró en las poblaciones de origen africano elementos básicos de la doctrina cristiana pero al mismo tiempo permitió que éstas elaboraran sus propias prácticas e interpretaciones, creando manifestaciones originales de religiosidad afrocatólica. Hacia mediados del siglo XVIII el incremento en las manumisiones aumentó notablemente la población de negros libres, quienes, ya fuera del dominio de los amos, se asentaron de forma dispersa a orillas de los numerosos ríos de la región pero en algunos casos continuaron reuniéndose periódicamente para conmemorar a sus santos y a sus muertos, ocasiones en las cuales, en ausencia de párroco, la organización y orientación del culto la asumían personas destacadas dentro de la comunidad. Estos eventos 
estimularon la consolidación de redes sociales y de parentesco que finalmente resultaron en la creación de nuevos poblados (De la Rosa y Moreno, 2006), y al mismo tiempo estimularon la existencia de esa particular forma de religiosidad dentro de la cual se incluyen elaboraciones musicales específicas como gualies, chigualos y alabaos. Los dos primeros corresponden a cantos que se entonan en el caso del fallecimiento de un angelito o niño menor de siete años, mientras que los alabaos aparecen durante los ritos fúnebres de los adultos y los festejos en torno a los santos ${ }^{3}$.

Vemos entonces cómo los alabaos son producto del peculiar proceso de evangelización que vivieron los pueblos de origen africano en el Pacífico colombiano. Desde muy temprano, los curas doctrineros echaron mano de los elementos más comunes de la cultura popular española de la época para llevar a cabo su misión en América; entre las estrategias que emplearon se destacan los romances, poesías plasmadas inicialmente por escrito cuyos versos poco a poco fueron transformados en canciones por la gente del común. Durante los largos siglos de la colonización estos relatos pasaron a América, donde continuaron su proceso de transformación y enriquecimiento ya en los nuevos contextos narrativos y musicales (Tobón, 2010).

En el caso que nos interesa, la relativa libertad para la creación de cultos y prácticas religiosas que encontraron estos pueblos les permitió apropiar los romances para convertirlos en expresiones originales, justamente los alabaos, que en la semana santa y las fiestas patronales narran la pasión y muerte de Jesucristo, pasajes bíblicos e invocaciones a santos $\mathrm{y}$ vírgenes; mientras que durante los velorios y novenas de muerto rememoran los pormenores de la vida del difunto, o describen su paso al más allá. Éstas se cantan sin acompañamiento de instrumentos en una estructura en la que cantaores y cantaoras lanzan un estribillo que la multitud responde; en ocasiones los alabaos conservan algunas palabras en latín.

En el Pacífico los velorios se realizan durante la noche que sigue al deceso y guardan similitud con los lloros descritos por Sandoval para la Cartagena colonial. Gran cantidad de gente se reúne en la casa del difunto para orar y entonar alabaos hasta el alba, el ambiente se llena de humo de tabaco mientras que botellas de licor, dulces y la comida que la familia ha dispuesto para la ocasión pasan de mano en mano. En las afueras de la casa, algunos de los asistentes narran cuentos, echan chistes, juegan dominó y se enamoran. En un velorio adulto se puede cantar, por ejemplo, "Ya llegó la muerte / que me viene a ver / la muerte no es hombre / la muerte es mujer" (Velásquez, 2000, p. 140), "Ya los ángeles lo llevan / a los reinos de la gloria / y lo ponen en presencia / de la divina custodia" (Ibid., p. 146), o "Dios te salve María / llena de gracia / peregrina del alma / se va y nos deja / adiós, querido hijo / dice la madre / hasta que junto en el cielo / digamos gloria" (Ibid., p. 152 y 153).

Pasado el entierro se realiza un novenario durante las noches siguientes. La parte más importante del rito se presenta al final de la última noche del novenario pues se considera que es en este momento cuando el difunto abandona definitivamente la tierra; para ésta la familia prepara un altar con telas blancas que penden del techo, flores, velas, imágenes sagradas, alguna foto del difunto y mońos o mariposas negras en tela o papel, esto se conoce como "tumba de cuerpo presente". Hacia el final de la noche la intensidad de los alabaos arrecia, al tiempo que los deudos empiezan a desmantelar el altar, cantan algo como "Levanten la tumba / del cuerpo presente / se va un pecador / en vida y en muerte" (Ibíd., p. 158) o "Levanten la tumba /levántenla ya, / que el alma se ausenta / pa' nunca jamás. / Adorar el cuerpo, / dorar la cruz, / dorar el cuerpo / de mi buen Jesús, 
/ de mi buen Jesús" (Ministerio de Educación Nacional, 2003). Mientras que los velorios de adultos son motivo de tristeza para las familias, se dice que la partida de un niño es fuente de alegría pues el cielo ha ganado un ángel, de modo que no debe haber lugar a la aflicción; en los velorios de angelito tradicionales se realizan juegos e igualmente se cantan gualíes o chigualos como este: "Este niño llora / no hay quien lo consuele / el último arrullo / de su madre quiere" y justo antes del entierro "Si se embarca / y se va / buen viajeee!” (Ibid., p. 155).

En el caso de las fiestas patronales, los alabaos y la música "profana" se hacen presentes en distintos momentos, de acuerdo con el contexto en el cual transcurre cada fase del rito. Las poblaciones del Pacífico aprendieron a "autoregular" sus fiestas, combinando las procesiones, eucaristías y rezos con baile, música y licor; la antropóloga Nina de Friedemann distinguió éstos como dos contextos religiosos distintos pero complementarios, que se combinan sin contradicción (Friedemann, 1969). Dentro del contexto que se realiza independientemente de las instituciones civiles y religiosas se presentan las balseadas, "paseos acuáticos" por el río que hacen los pobladores con las imágenes de sus santos sobre una balsa al ritmo de las chirimías en el norte, o las marimbas en el sur.

Durante la fiesta en honor a la Virgen de la Candelaria en Paimadó, un pequeño poblado afrocolombiano del Chocó, es posible observar cómo a lo largo de las procesiones en tierra los alabaos alternan con marchas tranquilas que tocan las chirimías mientras se recorren las calles del pueblo hasta el momento en que los santos y sus devotos regresan al parque central, frente a la iglesia. Entonces, la música se acelera y la gente "pone a bailar" a los santos moviendo las andas al compás de la música mientras les "dan" licor, diciendo que la virgen y san José son novios. La víspera del dos de febrero, día dedicado a la virgen, la fiesta toma tintes de carnaval; la gente va disfrazada por las calles del pueblo, bailando con energía y aprovechando para ventilar asuntos de interés colectivo mediante críticas cantadas como esta: "la salud se está muriendo / y el galeno no llegó / esperamos este año / un médico en Paimadó” (De la Rosa y Moreno, 2006).

No obstante las particularidades del proceso evangelizador que estimularon cierto grado de independencia religiosa y musical, éste no estuvo exento de conflicto. Mientras que durante el siglo XVII en Cartagena el jesuita San Pedro Claver luchaba por evitar los toques de tambor por considerarlos portadores de idolatrías, la historia oral de los pobladores del Pacífico sur cuenta cómo en el poblado de Barbacoas (Nariño)

[...] llegó un cura, su nombre Jesús Mera. El sacerdote al mirar que la gente se dedicaba mucho a gozar con la marimba a bailar, él vio que la marimba era diabólica y por lo tanto ninguna persona que fuera salva podía bailar marimba. Fue así que cuando llegaban los dueños de los bailes, o sea de marimba, o sea de los salones donde tocaban la marimba, a confesarse, él les decía que no podía confesarlos porque ellos tenían una marimba en su casa. Que para poderlos confesar debían deshacerse de la marimba, debían botar la marimba al río o quemarla. Así fue dejando el pueblo de Barbacoas sin salón de marimba. No contento con esto, tomó el río Patía y se vino río abajo haciendo lo mismo, botando las marimbas al río. Persona que tenía la marimba no la confesaba, y para poderla confesar tenía que botar la marimba al agua (Agier, 1999, p. 225).

Algo similar sucedió en el Chocó donde, a inicios de la década de 1960, las autoridades religiosas del departamento criticaban la forma como los afrochocoanos ejecutaban sus ritos fúnebres, calificándolos como fiestas ridículas: 
3 I O LINA DEl Mar Moreno Tovar

Sólo en el Chocó ha de existir esa abominación del noveno día en que se congregan gentes de toda edad y condición, festivos y alegres, porque los 'deudos fueron ya al pueblos par comprar los bastimentos': y en llegando se ponen mesas propias y prestadas, dentro y fuera de la casa mortuoria, se juega a naipes, a las damas, al dominó; se cantan versos disparatados, se cuentan cuentos y se come en abundancia... (La aurora apud. Velásquez, 2000, p. 158. Cursivas en el original).

En efecto, la historia de la música negra ha transitado entre la cristianización forzada y la resistencia, en un proceso que le ha impreso un carácter original a las melodías que hoy se entonan en Afrocolombia. La música sagrada que acompańa los rituales fúnebres y las fiestas patronales constituye una expresión del contrapoder que ejercieron los africanos y sus descendientes frente a la evangelización forzada que incluía la conversión total de esas poblaciones a la música europea (Carvalho, 2003).

Por fortuna, ese intento permanece inacabado debido a la persistencia de tercas memorias que, como hemos visto, se han colado en la espiritualidad de las y los afrocolombianos. Esas memorias producidas en contextos mayoritariamente ágrafos tanto en África como en América se han apoyado para su supervivencia en estrategias distintas a la escritura, entre los cuales destacan la oralidad y la expresión corporal (Maya, 2005, p. 340-360). En ambos casos, la música constituye una herramienta central para su reproducción: el ritmo de los tambores, los alabaos, el baile enérgico, conducen al trance que permite la comunicación con los ancestros. No en vano los afrocolombianos utilizan el mismo tipo de cantos para sus santos y para sus muertos; los santos son ancestros mayores, están presentes con todos los sentimientos humanos como el amor y la ira pero tienen el poder para hacer que cese la lluvia si se les mete de cabeza al río, pero también de enfurecerse y causar estragos si su fiesta no es lo suficientemente vistosa o no se les permite bailar lo suficiente al ritmo de la chirimía. La historiadora afroamericanista Adriana Maya ha señalado incluso la existencia en los alabaos de términos como primo, tío y hermano dirigidos a los santos como forma de re-crear parentescos simbólicos (Ibid.).

En estos espacios las narraciones, músicas y el ejercicio lúdico de la crítica social cantada permiten simultáneamente que la oralidad cambie y permanezca, de la misma manera que lo hacen los pueblos cuando echan mano de su acervo cultural al responder a los desafíos que les presenta el entorno para asegurar la conservación de sus lazos sociales. Por otra parte, la música se ha hecho cuerpo que baila, adora y comunica. Más allá de la ambigua relación de occidente con el cuerpo negro, subyace el vínculo entre éste, la música, la espiritualidad y la memoria. Como señala Benítez Rojo (1998), existe una "cierta manera" de hacer las cosas entre los hijos americanos de África (él la circunscribe al Caribe), una ritmicidad peculiar que atraviesa todas las actividades de la vida cotidiana, que conocemos pero no podemos describir y que antecede a la música: es la polirritmia, coexistencia de ritmos superpuestos que combinan sus métricas y se manifiesta en variados ámbitos de la vida social de los pueblos afrodescendientes (1998, p. 32-38). Allí, en ese ritmo temido y castigado pero inasible, fue donde se encarnó la memoria de modos que no fue posible desestructurar por completo.

\section{Epílogo: cantos de desarraigo y explotación}

Quiero concluir señalando brevemente que este proceso de reproducción cultural de la memoria por medio de la música continúa 
vigente entre los afrocolombianos, quienes han encontrado nuevas formas de actualizar música y memoria. Casos representativos los constituyen el grupo de fusión Chocquibtown y la chirimía Rancho Aparte, ambos compuestos por jóvenes chocoanos que a su modo le cantan al mundo sobre el desarraigo, la discriminación, la histórica explotación de la riqueza y la mano de obra afro en el Pacífico pero también sobre su pueblos, sus fiestas, su forma regional de hablar, bailar y hacer ${ }^{4}$. Chocquibtown presenta una combinación de músicas tradicionales con otros ritmos afroamericanos como el reggae y el hip-hop; la canción Oro es una muestra interesante de su trabajo, en ella se narra que "A mi tierra llegó un fulano / llevándose todo mi oro / [...] vestido de blanco entero / y con acento extranjero / prometió a cambio de oro / dejarme mucho dinero / el tipo de quien les hablo / nunca mas apareció / cogió mi metal precioso / y todo se lo llevo [...] / to' mi oro / se acabao' / los dueños son empleados / mas pobreza ha llegado / la inocencia se ha marchao' / y de aquí no me voy / de esta tierra yo soy / mi alma es como los ríos / camino recorrido" (Chocquibtown, 2008).

Por otro lado, Rancho Aparte es una agrupación que utiliza los instrumentos clásicos de la chirimía. Recientemente ha ganado reconocimiento por su canción De quién es la tierra, cuya letra denuncia el destierro que están afrontando los pueblos afrocolombianos en el Pacífico: “[...] muy temprano en la mañana / se levantaba Josué / sońando y las mismas ganas de cultivar la tierra que era de él / allí vivieron sus padre, viven sus hijos también / llevan una vida estable, para ellos era su edén / pero llegó la mañana y trajo consigo el dolor / tiros gente asesinada llanto impotente hay por dios / pobre gente desterrada, su edén desapareció / ahora ya no queda nada, de quién es la tierra pregunto señor /[...] la tierra ya no es de aquel que la cuida, del campesino que trabaja por su familia / sus corazones lloran, todo es a las malas, teniendo que soportar estallidos y balas (...) / lo que era paraíso, edén del campesino / ahora es morada predilecta del asesino” (Rentería, 2011).

Aunque me es imposible profundizar sobre las implicaciones de estas nuevas creaciones musicales de los pueblos afrocolombianos, quisiera brevemente dejar abierta una reflexión. Hoy es relativamente fácil que públicos internacionales accedan a músicas tradicionales, algunas con carácter sagrado, de pueblos ubicados en confines recónditos. La posibilidad de escuchar músicas indias, africanas, tibetanas, amazónicas o afroamericanas se ha vuelto cotidiana y para algunos sectores su consumo se ha convertido incluso en un símbolo de estatus. Este es uno de los resultados de la globalización y el multiculturalismo, fenómenos que si bien han permitido una circulación amplia de símbolos también ha contribuido a que el contenido de éstos se desgaste. En el ámbito musical Carvalho (2003) ha llamado la atención sobre la canibalización cultural que experimentan las músicas tradicionales afroamericanas cuando son apropiadas por públicos externos y convertidas en World music mediante un proceso de conversión a los cánones estéticos de masas requeridos para su comercialización, a costa de la pérdida de los significados simbólicos que las soportan, del hecho de que sus comunidades productoras de base continúen siendo en muchos casos, pobres y marginadas, y de que la relación con esas músicas se basa en expectativas orientadas por los estereotipos largamente conocidos, que ya hemos seńalado.

En ese sentido quisiera resaltar que los ejemplos de Chocquibtown y Rancho Aparte muestran dos facetas de la situación que atraviesan las músicas afroamericanas en el presente. El trabajo de estas agrupaciones sintetiza el poder comunicativo de las músicas afrocolombianas con su capacidad de denunciar los atropellos que sus creadores han vivido a lo largo de la historia y 
la nueva diáspora a la que se ven enfrentados hoy como consecuencia de la guerra que fractura a Colombia. En ese sentido, los procesos de actualización de las músicas tradicionales del pacífico nos dejan ver cómo se renuevan los vínculos históricos que han privilegiado la música como portadora de memorias colectivas y crítica social; al tiempo que se convierten en una estrategia que contribuye a visibilizar la existencia histórica de los afrodescendientes en América, la persistencia de su marginación y sus reivindicaciones como pueblo.

Por otro lado, es inevitable poner estas dinámicas en paralelo con las que describe Carvalho para el caso de las músicas afrobrasileras que han sido cooptadas por el mercado hasta perder los profundos sentidos estéticos, lúdicos, espirituales y críticos que mantuvieron durante largos periodos históricos. ¿Cómo lograr entonces que las sociedad nacionales y el mundo globalizado escuche lo que estos pueblos tienen para decir mediante su creación musical? El Estado y las sociedades nacionales deben apropiarse de éstos como patrimonios culturales invaluables, no para entregarlos al mercado, sino para comprender mejor la diversidad que les habita y relacionarse con ésta más allá de los estereotipos y las expectativas raciales, de modo que estos mensajes pueda circular sin que la música pierda su sentido simbólico y su importancia social.

\section{Afrocolombian music: between spirituali- ty and social criticism.}

abstract music production and enjoyment is one of the themes more commonly associated to African origin peoples. Whereas, beyond the representations of the black musician - happy and good dancer - underlie religious and social functions expressed through musical creations, which have been central for the cultural reproduction of the Afrodescendent peoples. The article examines the historical relationship between spirituality, social criticism and music to comprehend how has the music been a vehicle of corporal memory and in this way, contribute to the desnaturalization of the stereotypes that simplify the relation between black people and musical creation.

keywords Afrocolombians. Music. Celebrations. Funeral rites. Spitiruality.

\section{Notas}

1. Aunque el texto de Posada Gutiérrez data de 1865, los hechos que narra se refieren a las primeras décadas del siglo XIX, cuando visitó la ciudad como secretario de Simón Bolívar (De la Rosa y Moreno, 2005: 125).

2. El litoral Pacífico está compuesto por una extensa selva húmeda tropical que en la actualidad se extiende entre los límites fronterizos con Panamá al norte y Ecuador al sur, la cordillera occidental al oriente y el océano Pacífico al occidente. Allí los cautivos africanos fueron introducidos masivamente a partir de 1640 para trabajar sobre todo en la minería del oro. Las condiciones del terreno y la naturaleza de la actividad minera estimularon una ocupación del espacio basada en asentamientos dispersos que se mantiene hasta el presente. En esta región se ubica la totalidad del departamento del Chocó, así como parte de los departamentos de Valle, Cauca y Nariño. La población del litoral continúa siendo mayoritariamente de origen africano, en algunos casos ésta alcanza el 85\% del total. Aunque el Pacífico afrocolombiano puede ser visto como una región cuyos habitantes negros comparten gran cantidad de elementos culturales, existen matices y variaciones importantes entre las poblaciones ubicadas al norte, en el departamento del Chocó, y las que se asientan aproximadamente desde el puerto de Buenaventura, en el departamento del Valle, hacia el sur; esto es importante, ya que también implica diferencias notables en cuanto a los estilos musicales presentes en cada sub-región.

Aunque estas conmemoraciones y su acompañamiento musical son recurrentes a lo largo de toda la región, es importante anotar que en otros espacios la música tradicional afrocolombiana del Pacífico norte, donde destacan las chirimías de origen español compuestas por tambora, platillos, caja y flauta travesera, difiere notablemente de la del sur, donde predominan 
los grupos de percusiones compuestos por marimbas, cununos y guasás (Dediego, 2004, p. 20). Los cununos son tambores cónicos y se distinguen como macho y hembra según su tamańo. Por su parte, los guasaés son tubos de madera rellenos de semillas. Tanto marimbas como guasaés son elaborados con madera de chonta. Aunque algunos autores destacan la africanía presente en la marimba, otros han señalado que ésta es herencia de los mayas guatemaltecos (Arocha, 2011; García, 2009).

3. Los cununos son tambores cónicos y se distinguen como macho y hembra según su tamaño. Por su parte, los guasaés son tubos de madera rellenos de semillas. Tanto marimbas como guasaés son elaborados con madera de chonta. Aunque algunos autores destacan la africanía presente en la marimba, otros han señalado que ésta es herencia de los mayas guatemaltecos (Arocha, 2011; Fundación BAT).

4. Aunque distintas, las trayectorias de estas dos agrupaciones constituyen un buen ejemplo del creciente reconocimiento que las músicas negras están adquiriendo dentro y fuera de Colombia. Ambos son grupos relativamente jóvenes. Chocquibtown lanzó su primer disco en 2006, ha grabado tres álbumes, en 2010 fue ganador del premio Grammy Latino en la categoría canción alternativa y su música es cada vez más reconocida en el contexto internacional. Mientras tanto, Rancho Aparte se fundó en 2005, fue ganador del Festival de Música del Pacífico "Petronio Álvarez” en el año 2007 y su trabajo tiene gran figuración, sobre todo en el Pacífico.

\section{Referências bibliográficas}

AGIER, Michel. "El carnaval, el diablo y la marimba: identidad ritual en Tumaco". In: AGIER, M.; ÁLVAREZ, M.; HOFFMANN, O. y RESTREPO, E. (eds.). Tumaco: haciendo ciudad. Bogotá: ICANH, IRD, Universidad del Valle, 1999.

AGUDELO, Carlos. Retos del multiculturalismo en Colombia. Politica y poblaciones negras. Medellín: La Carreta Editores, 2005.

AROCHA, Jaime. Marimbas y méndigos. El Espectador. Bogotá, 19 de septiembre de 2011. Disponible en: http:/www.elespectador.com/impreso/opinion/ columna-300486-marimbas-y-mendigos. Acceso 9/10/2011.

ARROYO, Joe. Rebelión. 100 éxitos del siglo. Bogotá: Discos Fuentes, 2010.
BENÍTEZ ROJO, Antonio. La Isla que se Repite. Madrid: Editorial Casiopea, 1998.

CARVALHO, José Jorge de. La etnomusicología en tiempos de canibalismo musical. Una reflexión a partir de las tradiciones musicales afroamericanas. Trans Revista Transcultural de Música, n. 7, 2003. Disponible en: http://www.sibetrans.com/trans/a212/ la-etnomusicologia-en-tiempos-de-canibalismo-musical-una-reflexion-a-partir-de-las-tradiciones-musicales-afroamericanas. Acceso 9/10/2011.

CHOCQUIBTOWN. Oro. Bogota: National Records (EUA), 2008. 1CD (ca. $65 \mathrm{~min}$ )

DEDIEGO, Madolia. Danzas y ritmos folclóricos del Chocó. Nueva revista colombiana de folclor. Bogotá, v. 7, n. 23, 2004.

DE LA ROSA, Laura, MORENO, Lina del Mar. Tras las huellas de la Candelaria en los litorales colombianos. Memorias. Revista digital de Historia y arqueologia desde el Caribe. Barranquilla: Universidad del Norte, año 3, n. 5, 2006. Disponible en: http://redalyc.uaemex.mx/src/inicio/ArtPdfRed. jsp?iCve $=85530505 \& \mathrm{iCveNum}=0$

Virgen de la Candelaria: fiestas, historias y huellas entre el Caribe y el Pacifico. Tesis (pregrado en antropología). Facultad de Ciencias Humanas, Universidad Nacional de Colombia, Bogotá, 2005.

DE SANDOVAL, Alfonso. naturaleza, policia sagrada i profana, costumbres i ritos, disciplina y catechismo de todos los etíopes, (De Instauranda Aethiopum Salute). Sevilla:Francisco Lyra Editor, 1627. In: MAYA RESTREPO, Luz Adriana. Brujería y reconstrucción de identidades entre los africanos y sus descendientes en la Nueva Granada, siglo XVI. Bogotá: Ministério de Cultura, 2005.

FUNDACIÓN BAT. Marimba de Chonta. Bogotá, 2000. Disponible en: http://www.fundacionbat.com. co/noticia.php? idnot=586. Acceso 9/10/2011

FRIEDEMANN, Nina de. Contextos religiosos en un área negra de Barbacoas (Nariño, Colombia). Revista Colombiana de Folclor. Bogotá, v. 10, 1969. p. 60-83 Cabildos negros: refugios de africania en Colombia. Caracas: Universidad Católica Andrés Bello, 1988.

GARCÍA, Carlos. Marimba de chonta, en el pacífico colombiano. Revista Semana. Bogotá, 12 de octubre de 2009. Disponible en: http://www.semana.com/ on-line/marimba-chonta-canto-africano-pacifico-colombiano/129886-3.aspx. Acceso 9/10/2011.

JIMÉNEZ, Orián. El Chocó: una paraíso del demonio. Nóvita, Citará y el Baudó, siglo XVIII. Medellín: Universidad Nacional de Colombia, 2004. 
LA AURORA. Revista del vicariato apostólico de Quibdo. 1960.

MAYA Restrepo, Luz Adriana. Brujería y reconstrucción de identidades entre los africanos y sus descendientes en la Nueva Granada, siglo XVI. Bogotá: Ministerio de Cultura, 2005.

MINISTERIO DE EDUCACIÓN NACIONAL. Atlas de las culturas afrocolombianas. Bogotá, 2003. Disponible en: http://www.colombiaaprende.edu.co/html/ etnias/1604/article-82924.html. Acceso 1/10/2011.

NAVARRETE, María Cristina. Prácticas religiosas de los negros en la colonia. Cartagena siglo XVII. Cali: Facultad de Humanidades, Universidad del Valle, 1995.
POSADA Gutiérrez, Joaquín. Memorias Histórico Politicas. Bogotá: Foción Mantilla, 1865.

RENTERÍA, Edwin M. De quién es la tierra. Canción inédita. 2011.

TOBÓN, Alejandro. "Romances religiosos: de la España medieval a los rituales negros en el Atrato". In: OCHOA, J. S.; SANTAMARÍA, C. y SEVILLA, M. (Eds.). Músicas y prácticas sonoras en el Pacifico Afrocolombiano. Bogotá: Editorial PUJ, 2010.

VELÁSQUEZ, Rogerio. Fragmentos de historia, etnografía y narraciones del Pacifico colombiano negro. Bogotá: ICANH, 2000.

WERNER, Erick. Los Emberá y la gente negra del Atrato bajo el dominio español. Siglo XVIII. Bogotá: ICANH, 2000.

\section{autor Lina del Mar Moreno Tovar \\ Doctoranda em Antropologa Social / ENAH-México}

Recebido em 18/10/2011

Aceito para publicação em 18/10/2011 